\title{
Review of On the Other Side of Life
}

To the Editor:

In the Winter 2000 issue of the Journal, Emily Williams Kelly reviewed my book, On the Other Side of Life. Here, I would like to respond to some of her criticisms because I think they are either 
unfair or unfounded and thus may fail to give the reader an accurate assessment of this volume.

Let me begin by asserting that I wrote this book because I wanted to read such a work, namely, a cross-disciplinary exploration in the form of dialogues that could inform me about the standpoint of science and philosophy regarding near-death experiences (NDEs). Over several months, I conversed with distinguished scholars in the fields of psychology, physics, biology, neurophysiology, theology, and philosophy; and because of the perspicacity and intellectual range of my interlocutors, I believe they did help to articulate new and useful concepts for the theoretical and philosophical understanding of NDEs.

Now, in fairness to this book, it should be noted that I began the research and writing for On the Other Side of Life fully ten years ago. As far as the data are concerned, NDE research has certainly provided many findings since then, which of course would have been taken into account were the book to be written today. Still, as far as the views are concerned that were proferred by the eminent personalities I interviewed, I do not think they have lost any of their value because they address many of the perennial factors that need to be taken into account in any comprehensive explanation for NDEs, such as the nature of NDEs, brain functioning, and consciousness itself, as well as the relation of quantum physics to NDEs. The meaning and the mystery of NDEs have certainly not yet been entirely unveiled and will not be for a long time, if ever.

Kelly wrote that she found herself "becoming increasingly uncertain and uneasy about the extent of Valarino's exposure to or knowledge about near-death research" (p. 124). I would like to stress that, apart from the fact that the book has been written some years ago, the place where I wrote it is not insignificant either. I live in Switzerland and NDEs were poorly known in my country some ten years ago. Although I had access to Anglo-American NDE literature and was in contact with some researchers at that time, as a newcomer to the field I did not then know the large circle of NDE researchers and NDErs whose collegial friendship I enjoy today. The NDE knowledge I have acquired in this past decade is, I trust, present in my latest NDE book, which I finished only a month ago.

As for the interviewees, Kelly wrote that they were "for the most part, too uninformed about the phenomenon of NDEs to keep the discussion anchored in the reality of what we currently know about NDEs" (p. 123). I do not think that the NDE expertise of Kenneth Ring, with whom I 
conducted the longest of the six interviews ( 75 pages), can in any way be questioned, so I will not comment further on that point other than to raise a quizzical eyebrow at the use of Kelly's adverb, "apparently" (p. 124), in connection with his prominence in the field. As far as the other five interlocutors are concerned, it is true that they are not NDE specialists themselves, although they have a good understanding of the phenomenon. On the contrary, they were chosen precisely for the eminence they had achieved in their specific fields so that the reader could benefit from their insights about the NDE phenomenon from the perspective of their own professional specialities.

Kelly objected that "Not only Monsignor Vernette, but Girard, Vincent, and Chauchard seem to be committed Christians to some degree" (p. 124). Except for Jean-Pierre Girard, who is Swiss, all these persons are French and more than 90 percent of the French population belongs, however nominally, to the Catholic faith. That is hardly a problem in itself inasmuch as all of them stated very clearly what their beliefs were and, because of their intellectual integrity, these beliefs definitely did not interfere with their scientific reasoning and reflection. Therefore, the reader is hardly being exposed to any covert influence attempt in this regard. My only regret concerning the choice of my interlocutors is the fact that none of the skeptical scholars I contacted agreed to be interviewed. This was a pity because I had been very eager to include a wide spectrum of perspectives on the NDE in my book.

Another of Kelly's criticisms concerns the two short testimonies I included at the beginning of the book in order to illustrate the theoretical description of NDEs I provided. She wrote that "the two experiencers interviewed seem odd choices ... since neither of them had a particularly rich experience" (p. 124). I do not think there is such a thing as an uninteresting or poor NDE. I believe all of them are valuable and worth being looked at and they certainly have a deep importance and meaning for the NDEr. The "odd choices" were the following: a drug addict who was able to quit using drugs nine months after undergoing his NDE, after 20 years of heavy drug addiction (I was mostly interested in the aftereffects of this NDE), and a professor of medicine who, as a result of an allergy, suffered a heart attack following a bee sting and who certainly had the necessary intellectual discernment to analyze his NDE with the critical and trained mind of a scientist. Truly, I do think most readers would find these testimonies most worthwhile, even if Kelly failed to be impressed with them.

In Chapter 2, "Analysis of the NDE and Its Successive Stages, Illustrated by Experiencer Accounts," I broke the phenomenon down 
into 31 components, and then commented on and illustrated them by reference to testimonies of people who have undergone NDEs. Those quotes are, in Kelly's words, "based almost entirely on Ring's book Heading Toward Omega (Ring, 1984) [Melvin Morse's Transformed by the Light (Morse and Perry, 1992) and Raymond Moody's Life after Life (Moody, 1975) are the only other works cited]" (p. 124). Indeed, I quoted exclusively from those books for a straightforward reason any author would understand: On the Other Side of Life has been published in 11 languages so far, including Chinese, and it simply was more convenient for copyright permission purposes to limit quotes to three books only. In any case, I can certainly reassure Kelly that I did read more than just those books, as the large bibliography (21 pages) will attest. And purely for reasons of space in an already long book, I chose to limit my bibliography to books and therefore did not include NDE-related articles in my very long bibliography; but that does not mean I did not read them!

Another of Kelly's somewhat captious criticisms concerned my discussion of the life review, whose general importance in the NDE scheme of things she seemed to question. In her remarks, however, she completely missed the point by conflating frequency of occurrence with significance. Obviously, how often a particular feature of the NDE occurs is merely a statistical parameter, and in itself says nothing about its importance either to the experiencer or to those of us who hope to learn from NDEs. (And even here, Kelly's own figures can be challenged; Bruce Greyson [1990], for example, found evidence for a life review in about a quarter of his NDE respondents.) In this connection, it may be useful to mention Ring's discussion of this phenomenon in our recent book (published after On the Other Side of Life), Lessons From the Light (Ring and Elsaesser-Valarino, 2000), where he devoted two entire chapters to the life review and clearly established its credentials as one of the deepest sources of ethical insight that stem from the NDE-which only confirms the essential argument I had striven to make in On the Other Side of Life.

I would like to refute another of Kelly's criticisms. She wrote that "For example, she perpetuates the popular belief that NDEs occur when a person is "clinically dead'" (p. 125). On the contrary, on the first page of On the Other Side of Life, I very clearly declared: "This immediately gives rise to the question of what is meant by 'death,' which is indeed a difficult concept to define... Consequently, I have avoided using the term 'clinical death' and have kept to the more vague notion of 'neardeath state." 
Finally, I want to respond to Kelly's reproach that 'Valarino's objectives seem much more evangelical than scientific" (p. 128). That is an easy rebuke to make, I suppose. Of course, I do hope that my way of presenting the near-death experience will be perceived by most readers as scientific in tone. Certainly, I can attest that all of my interlocutors (except Monsignor Vernette) are university professors and undertook their analyses of the nature, meaning, and implications of the NDE from a scientific point of view. However, on a personal note, I will just conclude by saying that after having studied NDEs for so many years now in a very intensive way, my own fascination with them only grows stronger, as does my belief that it is very important to talk and write about NDEs and to allow those interested to get more deeply acquainted with this transcendental experience. It is then ultimately their responsibility to find deep down in their hearts the meaning and personal implications of NDEs for their own lives. Of course, my book was written with this end in mind, and I trust that most readers will find it useful in that regard.

\section{References}

Greyson, B. (1990). Near-death encounters with and without near-death experiences: Comparative NDE scale profiles. Journal of Near-Death Studies, 8, 151-161.

Kelly, E. W. (2000). [Review of On the Other Side of Life: Exploring the Phenomenon of the Near-Death Experience, by E. Elsaesser-Valarino]. Journal of Near-Death Studies, $19,123-130$.

Ring, K, and Elsaesser-Valarino, E. (2000). Lessons from the Light. Portsmouth, NH: Moment Point Press.

Evelyn Elsaesser-Valarino

Directrice

Bibliothèque de la Faculté de droit Uni Mail

Bd. du Pont-d'Arve 40

$\mathrm{CH}-1211$ Genève 4

Switzerland

e-mail: Evelyn.Valarino@droit.unige.ch 